NP5 (continued)

findings into practice by supporting efforts to improve access to healthy, affordable food and places to be active. Funding: USDA Grant \#2011-68001-30103

\section{NP6 Effectiveness of Supports for Family Mealtimes on Obesity Prevention Among Head Start Preschoolers: The Simply Dinner Study}

Holly Brophy-Herb, PhD, hbrophy@msu.edu, Michigan State University, Department of Human Development and Family Studies, 552 West Circle Drive, Room 7, Human Ecology Building, East Lansing, MI 48824; M. Horodynski, RN, PhD; D. Contreras, PhD; J. Kerver, RD, PhD; M. Stein, MSW; E. McClain, MSW, Capital Area Head Start; N. Kaciroti, PhD, University of Michigan; J. Lumeng, MD, PhD

Objective: To test the main, additive and interactive effects of 6 intervention components reflecting differing levels of supports for healthy family mealtimes on reducing childhood obesity.

Description: Using the Multiphase Optimization Strategy, we are currently testing 6 intervention components in a Screening Phase in Head Start families $(\mathrm{N}=520)$, which will result in the implementation and evaluation of a "final" intervention model in the Confirming Phase $(\mathrm{N}=250)$.

Evaluation: Screening Phase analyses will test, on an intent-to-treat basis using ANOVA models, whether each intervention factor has a significant effect on frequency of healthy, family mealtimes and dietary quality pre- to post-intervention.

Conclusions and Implications: Results will inform policy (e.g. where limited resources may be best allocated) and interventions (e.g. most effective strategies for promoting mealtimes).

Funding: USDA Grant \#2015-68001-23239

\section{NP7 HomeStyles: Shaping Home} \section{Environments and Lifestyle Practices to} Prevent Childhood Obesity- A Randomized

\section{Controlled Trial}

Carol Byrd-Bredbenner, PhD, RD, FAND, bredbenner@ aesop.rutgers.edu, Rutgers University, 26 Nichol Avenue, New Brunswick, NJ 08901; J. Worobey, PhD, FAPA; J. R. Martin-Biggers, MS, RD; N. Hongu, PhD, RD; G. Hernandez, MA

Objective: To create an effective, sustainable, populationlevel obesity-prevention intervention that enables and motivates parents of preschoolers to shape their home environment and lifestyle behavioral practices to prevent excessive weight gain in their children and compare its effectiveness to control condition participants.

Description: Intervention development and implementation was guided by Social Cognitive and Adult Learning Theories, community-based participatory research, and motivational interviewing. The randomized controlled intervention trial is delivered by in-home visitors or online to English and Spanish parents of preschoolers. Focus groups with parents guided development of intervention materials. Cognitive testing with parents was used to refine intervention materials.

Evaluation: Cognitive testing of intervention materials indicated high audience acceptance and satisfaction. Training of home visitation staff delivering the intervention in-home was rated highly satisfactory by staff. Instruments for benchmarking participants and assessing intervention outcomes are valid and reliable. Preliminary time $\mathrm{x}$ treatment analyses indicate that, compared to control group parents, experimental group parents had significant improvements in family support for healthy eating, parental modeling of healthy eating behaviors, and self-efficacy for preparing healthy family meals, reducing children's intake of sugary drinks, helping children get and keep a healthy weight, and teaching children about the selling intent and poor nutritional value of foods advertised on TV. Experimental group parents also reported significantly increased overall quality of life.

Conclusions and Implications: Year 5 activities which focused on recruiting and retaining participants will be summarized. Parent cognitions and behaviors along with home environments and family lifestyle behaviors that promote healthy child growth and development have the potential to prevent excessive weight gain in preschoolers. Funding: USDA Grant \#2011-68001-30170

\section{NP8 The Use of Coupons to Motivate Healthier Snack Food Choices Among Children: Results of the CHOMPS Pilot}

Sean Cash,PhD, sean.cash@tufts.edu, Friedman School of Nutrition Science and Policy, Tufts University, 150 Harrison Avenue, Room 127, Boston, MA 02111;

A. R. McAlister, PhD, Michigan State University; C. D. Economos, PhD, Tufts University; M. E. Lehnerd, MS; W. L. Adamowicz, PhD, University of Alberta; S. R. Howell, Tufts University; E. L. Satin-Hernandez, Shape Up Somerville; A. L. Gallop, Tufts University

Objective: Prior research has shown that children's independent food purchases in convenience stores are predominantly energy-dense, nutrient-poor (EDNP) foods. Little is understood about altering this behavior to improve children's diets. This multi-disciplinary intervention applies economic, psychological, and nutritional insights to explore children's autonomous food purchase behaviors. Description: During our two-year, USDA-funded pilot, the Coupons for Healthier Options for Minors Purchasing Snacks (CHOMPS) initiative introduced kids-only coupons in convenience stores with the goal of encouraging healthier snack purchases. Set in Somerville and Medford, MA, the intervention offered coupons of varying discounts for healthier snack alternatives paired with simple health and economic marketing messages. Additionally, individual interviews (incorporating language and cognitive 